\title{
Comparing the extent and pattern of use of social networking sites by medical and non medical university students: a multi-center study
}

This article was published in the following Dove Press journal: Psychology Research and Behavior Management

\author{
Salman Yousuf Guraya' \\ Mona Faisal Al-Qahtani ${ }^{2}$ \\ B Bilal $^{3}$ \\ Shaista Salman Guraya ${ }^{4}$ \\ Hamdi Almaramhy ${ }^{5}$ \\ 'Surgery Unit, Clinical Sciences \\ Department, College of Medicine, \\ University of Sharjah, Sharjah, UAE; \\ ${ }^{2}$ Department of Public Health, College of \\ Public Health, Imam Abdulrahman Bin \\ Faisal University, Dammam, Saudi Arabia; \\ ${ }^{3}$ School of Accountancy, Hubei University \\ of Economics, Wuhan, People's Republic \\ of China; ${ }^{4}$ Medical Education Unit, \\ College of Medicine, University of \\ Sharjah, Sharjah, United Arab Emirates; \\ ${ }^{5}$ Pediatric Surgery, College of Medicine, \\ Taibah University Almadinah \\ Almunawwarah, Medina, Saudi Arabia
}

Correspondence: Salman Yousuf Guraya Surgery Unit, Clinical Sciences Department, College of Medicine, University of Sharjah, Building M-27 PO Box 27272, Sharjah, United Arab Emirates Email salmanguraya@gmail.com
Objectives: Although use of social networking sites (SNSs) for fun and leisure is escalating, educational use of SNSs by students is low. Furthermore, there is a scarcity of data about the use of SNSs by students from different faculties. This study compared patterns and extent of use of SNSs among medical and nonmedical university students.

Methods: A 21-statement questionnaire was administered to the students of medical colleges of two Saudi universities and nonmedical students of two Chinese universities. Demographic data, nature of SNSs, and strategies used for sharing knowledge were collected and analyzed.

Results: Of 2,350 respondents, 92\% used SNSs for various reasons. Overall, $624(26.6 \%)$ students used SNSs for education and found these sites to be useful $(P=0)$. Educational use of SNSs was significantly higher in medical than nonmedical students $(P=0)$. However, nonmedical students found SNSs more useful for social connections than medical students, with mean rankings of 1,328 and 978, respectively. WhatsApp use was significantly greater among medical students, while WeChat was more popular with nonmedical students $(P=0)$. Conclusion: This study reports low use of SNSs for education by university students. For sharing knowledge, WhatsApp was more popular among medical students and WeChat for nonmedical students. This research demands educational reforms that can uniformly embed the use of social media in teaching and learning pedagogies across disciplines.

Keywords: social networking sites, Facebook, Twitter, Flickr, WeChat, education

\section{Introduction}

The advent of social media has generated tremendous enthusiasm and fun for opinion expression and information exchange. ${ }^{1}$ A range of Internet-based social networking sites (SNSs) are available, such as FaceBook, Twitter, YouTube, MySpace, WhatsApp, WeChat, Instagram, and LinkedIn. The estimated number of Facebook active visitors was reported to be 2.32 billion monthly in 2018, while that for Twitter has been projected to reach 275 million per month by the end of $2019 .^{2}$ An active user is a creator of an account who regularly uses their profile for several purposes, while a passive user engages with the platform primarily as a consumer of content, such as reading posts or tweets and watching videos or blogs. ${ }^{3}$ Active users of these SNSs have grown exponentially during the last 2-3 years. Each SNS has specific features and functionality. Facebook is predominantly used for social interaction and information sharing, whereas Twitter is essentially used for sharing views and breaking news. ${ }^{4}$ Facebook offers a technology-enhanced 
educational climate with a uniqueness for widening learning contexts by hybridizing a range of expertise. ${ }^{5}$ However, institutional restrictions, teachers' and learners' preferences, and a wealth of cultural virtues may deter a comprehensive application of Facebook for education. Unlike Facebook, Twitter integrates individual perceptions about events, and clients share information about their activities and remarks by creating followers. ${ }^{6}$

SNSs are perceived to be innovative and efficient tools for human communication that have changed the landscape of addressing the masses for public opinion, sharing information, and downloading videos, audio, and photos at any given time. The usage of SNSs is far-ranging and has been measured in terms of time spent on applications, status updates, and their level of connectivity. ${ }^{7}$ Recently, a systematic review and meta-analysis by Guraya investigated the use of SNSs by medical and allied health-science students, and reported that $75 \%$ used SNSs for general purposes and only $20 \%$ used these sites for sharing academic and educational information. ${ }^{8}$ The author has emphasized the need to educate tomorrow's doctors in enhancing their expertise in digital technology. Several other reports have elucidated the effectiveness of SNSs in enhancing the educational climate in higher education, such as by strengthening student-teacher interactions, ${ }^{9}$ facilitating in creating and sustaining effective engagements, ${ }^{10}$ learners' motivation toward their courses, ${ }^{11}$ and strong peer-to-peer interactions. ${ }^{12}$

The literature has shown that an increasing number of university students use SNSs for their teaching and learning by conveniently sharing course-content material, lectures, and handouts with other students..$^{13}$ The use of SNSs plays a pivotal role in distance-learning courses for university students. ${ }^{14}$ This underpins the significance of SN in educational scholarships. However, there is a dearth of research and poor understanding about the precise nature of SNS use for education, and there is no standard eplatform for sharing and delivering knowledge by SNSs in higher education. Furthermore, strategies used for sharing educational information by medical and nonmedical university students from various disciplines is not known. Understanding the explicit nature of educational use and primary forms of SNS use from a professional and educational standpoint and determining popular SNSs among medical and nonmedical students will potentially help educators to develop a common education-based digital framework. The current research aimed to capture similarities and dissimilarities in the extent and nature of use of SNS data from medical students of Taibah University (TU) and Imam Abdulrahman Bin Faisal University (IAFU), Saudi Arabia and nonmedical students of the Beijing Institute of Technology - School of Management and Economics (SME-BIT) and University of International Business and Economics (UIBE), China. The data may potentially draw the attention of educators in making a standard teaching pedagogy that could embed SNS media in existing curricula across institutions.

\section{Methods \\ Research design}

This cross-sectional study was conducted from October to December 2017 on all enrolled undergraduate medical and allied sciences students of TU and IAFU and undergraduate business and management-science students of the SME-BIT and UIBE. These countries share Asian geographical commonalities, with similar educational frameworks. At the same time, there is congruence in the range of SNSs being used in both countries. After obtaining ethical approval from the research ethics committees of relevant universities, a 21-statement validated Englishlanguage questionnaire was administered to the participants. ${ }^{15}$ Completion of the survey by participants was deemed to be informed consent. The first seven statements of the instrument pertained to the frequency of SNS use on a 5-point Likert scale of never (1), once a month (2), once a week (3), once a day (4), and three to five times per day (5). The remaining sections of instrument enquired about views of university students about educational effectiveness and mechanisms of use SNSs on a 5-point Likert scale. SurveyMonkey, online survey-development cloudbased software, was used for delivery of the questionnaire and data retrieval in TU and the UIBE. However, the survey was conducted through a paper-based mechanism at IAFU, the SME-BIT, and the UIBE.

\section{Study settings}

TU utilizes a classical 5-year MBBS competence-based problem-basedlearning curriculum. This program promotes clinical exposure of medical students right from the first year. In addition, well-structured portfolios, student-centered education, and clinical reasoning are embedded in the curriculum. The learning environment is enriched with an e-learning platform of TaskStream software that complements face-to-face learning with more flexibility for learners. At IAFU, the medical program consists of 1 preparatory year, 5 academic years, and one 
internship training program with eight clinical rotations. This interdisciplinary program consists of a thematic integrated system that includes problem-basedlearning by case-based and community-based strategies in a patientcentered learning philosophy. The SME-BIT and UIBE apply 4-year undergraduate programs using a blend of arts and science in all fields of business and primarily focusing on information systems, marketing, accounts and economics.

\section{Data analysis}

Data retrieved were analyzed using SPSS 20. Results of descriptive tests are shown by frequency distribution, graphs and clustered bar charts. The validity and reliability of the research instrument was verified by principal-component analysis and Cronbach's $\alpha$, respectively. Preliminary analyses demonstrated that all items of the questionnaire were arranged in an ordinal scale, so nonparametric tests were used for further inferential analyses where variables (instrument items) were arranged in a categorical format. CTo explore variations between observed and expected frequencies within each variable, $\chi^{2}$ was used. As a prerequisite for using other nonparametric data, the Mann-Whitney $U$ test was used and data normality cross-checked using one-sample KolmogorovSmirnov tests. In the event of a variable carrying a significant $z$-value $(<0.05)$, this would reject the null hypothesis that data were normally distributed. Consequently, nonparametric tests would be considered appropriate for comparison of responses from medical and nonmedical fields. The Mann-Whitney $U$ test compared differences in preferences and views of medical and nonmedical students. $P<0.05$ was considered significant.

\section{Results}

Of 3,000 invitees, we received 2,350 complete responses (response rate $78.33 \%$ ) that comprised 1,148 of 1,500 (76.53\%) frommedical students: 796 of 1,000 (79.6\%) IAFU and 352 of $500(70.4 \%)$ TU students. On the other hand, 1,202 of $1,500(80.13 \%)$ nonmedical students responded: 854 of $1,000(85.4 \%)$ UIBE and 348 of 500 (69.6\%) SME-BIT students. There were 1,332 of 2,350 (56.7\%) female and 1,018 of 2,350 (43.3\%) male respondents: $806(34.3 \%)$ third-year, $542(23.1 \%)$ second-year, 451 (19.2\%) fourth-year, 420 (17.8\%) first-year, and 131 $(5.6 \%)$ fifth-year students. The majority of respondents $(1,486 ; 63.2 \%)$ were aged $18-24$ years, $804(34.2 \%) 25$ 34 years, and $60(2.6 \%)$ students $>34$ years. Overall, $92 \%$ used the Internet for various reasons. Of those who used SNSs, 624 (26.6\%) found these sites useful for educational purposes. A total of 362 of 1,148 (31.5\%) medical and 262 of $1,202(21.1 \%)$ nonmedical students strongly agreed that SNSs matched their educational needs.

Figure 1 presents a clustered bar chart of observed frequencies for statements about SNS degree of usage by categorical variable. For the first "How often do you use social networking sites (eg, Facebook, Youtube, Twitter, Linkedin, and Flickr) to keep in touch with family and friends?", 986 of 2,350 (41.96\%) used SNSs for keeping in contact with their friends and family once a day. For the question "How often do you use email for sharing information for educational purposes?", 745 of 2,350 (31.70\%) used email once a week for sharing educational material. From the entire cohort, a great majority of respondents utilized SNSs once a week for education (Figure 1).

Figure 2 presents a bar chart of observed frequencies for students' usage of SNSs for education using a categorical variable: $1=$ strongly agree, $2=$ agree, $3=$ don't know, $4=$ disagree, and $5=$ strongly disagree. Most response was recorded for the 13th statement - "Social networking sites help me to access educational resources" — with 850 of 2,350 (36.17\%) strongly agreeing that SNSs were an informative educational platform. Regarding the usefulness of SNSs in education, for the 18th statement, "I have found social networking sites useful for sharing notes and lectures", 908 of 2,350 (38.64\%) agreed that they found SNSs to be useful for sharing notes and lectures, and for "I have found social networking sites useful for educational purposes", 920 of 2,350 (39.15\%) students strongly agreed that SNSs were helpful in their learning. In contrast, 674 of 2,350 (28.68\%) disagreed and 432 of $2,350(18.38 \%)$ strongly disagreed with the 21 st statement "I believe that social networking sites are inappropriate for sharing classroom materials, information, and discussing education related topics".

Figure 3 shows the most common SNSs used by medical and nonmedical students for educational purposes. WhatsApp was the most commonly used SNS for educational purposes by medical students: 428 of 1,148 (37.28\%) used it for educational purposes. In contrast, WeChat was reported to be the most common SNS for educational purposes by nonmedical students : 499 of $1,202(41.51 \%)$ nonmedical students used it for learning.

The results of the $\chi^{2}$ test of independence showed that all statements were significant at the $1 \%$ level of significance. This finding endorsed observed student's responses 


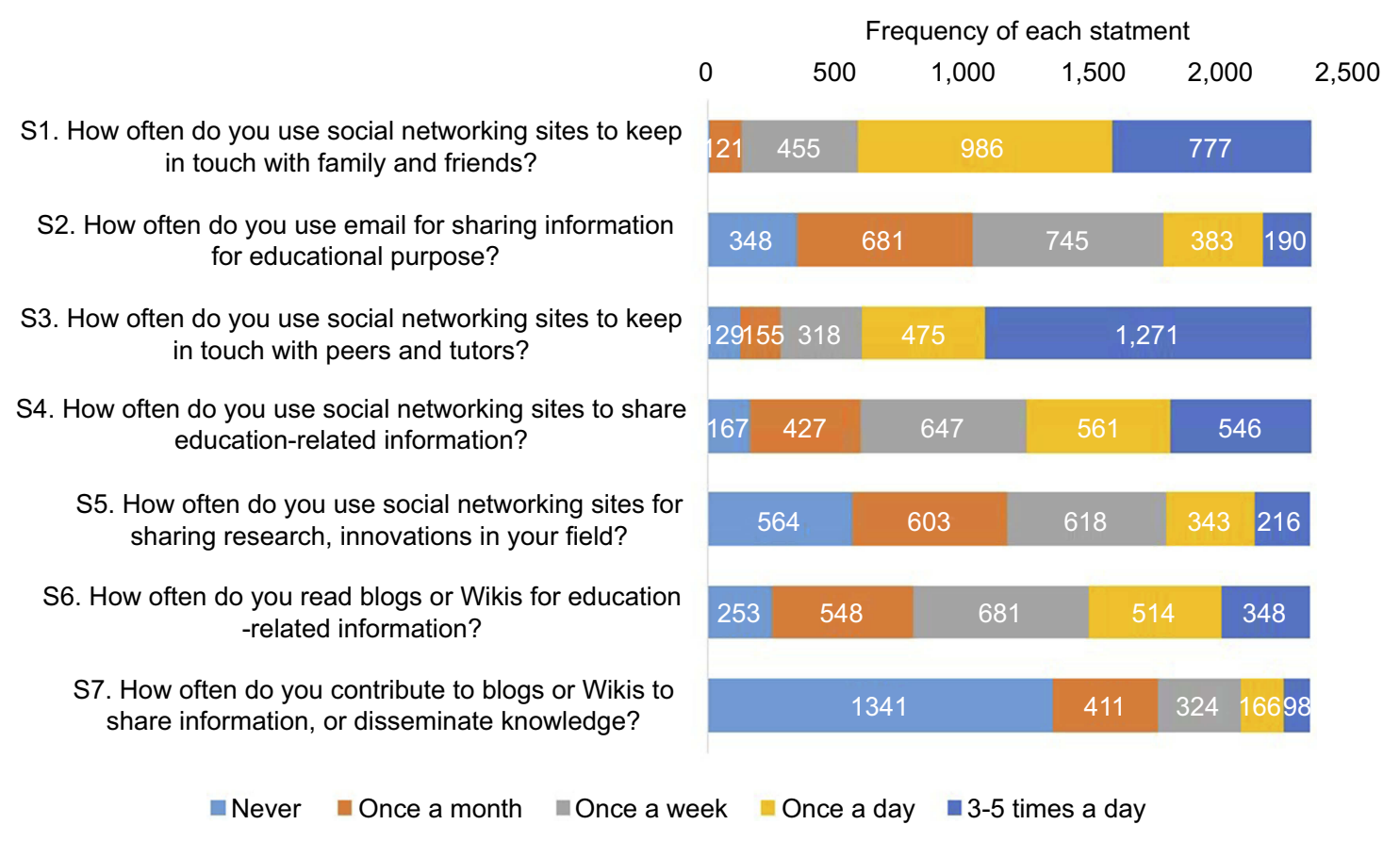

Figure I Observed frequencies of responses to statements about students' extent of the usage of social networking sites $(n=2,350)$.

being statistically varied due to differences in expected frequencies within each category on the defined Likert scale (Table 1). Data were not uniformly distributed, as each statement had significant $z$-value of $<0.01$, rejecting the null hypothesis that data were normally distributed on the one-sample Kolmogorov-Smirnov test.

Table 2 presents the validity and reliability of the research instrument. Principal-component analysis was applied to test the validity of the questionnaire. The Kaiser-Meyer-Olkin measure of sampling adequacy was 0.94 which indicated that the degree of common variance among the 21 statements was marvelous for principal-component analysis. Likewise, Bartlett's test of sphericity was significant, which showed the validity and suitability of the collected responses was recommended for principal-component analysis. The 18 statements were extracted into 3 components on the basis of Eigenvalues. The rule of thumb is that the eigenvalue must be $>1$. The first component was the use of SNSs for education, with an eigenvalue of 8.66 (41.23\% variance), second for the use of SNSs for professional development, with an eigenvalue of 2.25 (10.74\% variance), and third for the effectiveness of SNSs for education, with an eigenvalue value of 1.29 (6.15\% variance). The reliability of these factors was evaluated by Cronbach's $\alpha$.

The Mann-Whitney $U$ test was used to compare responses about SNSs for different purposes and the extent of usage of SNSs using six major factors (Table 3). We found significant variations in all factors among medical and nonmedical students that were significant at the 5\% levele. First, SNS usage for education was significantly higher in medical students than nonmedical students (mean rank 1,328 vs 978 for nonmedical students). Secondly, medical students used SNSs more for professional development than nonmedical students: 1,298 vs 1,055 for medical and nonmedical groups, respectively. Thirdly, medical students found social media more effective for education than nonmedical students (mean rank 1,218 vs 1,123 for nonmedical students). Lastly, medical students preferred more guidance and supervision on effective use of SNSs for their education than nonmedical students (mean rank 1,276 vs 1068 for medical and nonmedical groups, respectively). In contrast, nonmedical students (mean rank 1,218) found SNSs to be more useful for keeping in touch with friends than medical students (mean rank 1,134). Likewise, nonmedical students perceived SNSs to be inappropriate for educational purposes than medical students (mean rank 1,229 vs 1,117 for medical students.

\section{Discussion}

This is the first study to quantitatively compare the extent and pattern of social media use for learning by medical and nonmedical university students. Our research showed that $92 \%$ of students used SNSs for all purposes, and of those 


\begin{tabular}{|c|c|c|c|c|c|c|}
\hline & \multicolumn{6}{|c|}{ Frequency of each statement } \\
\hline 0 & 500 & 1,000 & 1,500 & & 2,000 & \\
\hline $\begin{array}{l}\text { S8. Social networking sites help me in collection of educational } \\
\text { materials }\end{array}$ & 720 & 936 & & 284 & 193 & 199 \\
\hline $\begin{array}{l}\text { S9. Social networking sites are helpful in collaborative and peer- } \\
\text { to-peer learning }\end{array}$ & 668 & 950 & & 361 & 216 & 6146 \\
\hline $\begin{array}{l}\text { S10. Social networking sites are useful in developing reading and } \\
\text { writing web skills }\end{array}$ & 577 & 791 & & 48 & 261 & 164 \\
\hline $\begin{array}{l}\text { S11. Social networking sites provide opportunity of virtual } \\
\text { meetings with other students and tutors }\end{array}$ & 630 & 866 & & 480 & 227 & 6 \\
\hline $\begin{array}{l}\text { S12. Social networking sites help me to communicate with peers } \\
\text { about class projects }\end{array}$ & 725 & 946 & & 266 & 210 & 184 \\
\hline $\begin{array}{l}\begin{array}{l}\text { S13. Social networking sites help me to access educational } \\
\text { resources }\end{array}\end{array}$ & 850 & 859 & & 226 & 195 & 203 \\
\hline $\begin{array}{l}\text { S14. Social networking sites help me to retrieve educational } \\
\text { references for research }\end{array}$ & 598 & 869 & & 402 & 318 & 149 \\
\hline $\begin{array}{l}\text { S15. Social networking sites facilitate my professional } \\
\text { development of technological skills }\end{array}$ & 543 & 982 & & 398 & 271 & 140 \\
\hline $\begin{array}{l}\text { S16. Social networking sites are useful in communicating with } \\
\text { classmates about course-related topics }\end{array}$ & 726 & 922 & & 294 & 179 & 215 \\
\hline $\begin{array}{l}\text { S17. I have found social networking sites useful during the pre } \\
\text { exam period when I get an instant answer/explanation from my.. }\end{array}$ & 605 & 604 & 462 & 44 & 41 & 225 \\
\hline $\begin{array}{l}\text { S18. I have found social networking sites useful for sharing notes } \\
\text { and lectures }\end{array}$ & 666 & 908 & & 334 & 204 & 212 \\
\hline $\begin{array}{l}\text { S19. I have found social networking sites useful for educational } \\
\text { purposes }\end{array}$ & 624 & 920 & & 386 & 211 & 180 \\
\hline $\begin{array}{l}\text { S20. Students need supervision and guidance for the appropriate } \\
\text { use of social networking sites for educational purposes }\end{array}$ & 716 & 805 & & 503 & & 324 \\
\hline $\begin{array}{l}\text { S21. I believe that social networking sites are inappropriate for } \\
\text { sharing classroom materials, information, and discussing ... }\end{array}$ & 259 & 515 & 674 & & 43 & \\
\hline
\end{tabular}

Figure 2 Observed frequencies of responses to statements about students' perceptions of the usage of social networking sites for educational purposes ( $\mathrm{n}=2,350$ ).

who used SNSs, only 624 (26.6\%) were using SNSs for educational purposes. Furthermore, the use of SNSs for education was significantly higher in medical students than nonmedical students, and medical students used SNSs for professional development much more than nonmedical students Finally, medical students found SNSs more useful for education than nonmedical students. However, nonmedical students used SNSs more frequently for keeping in touch with friends than education. In contrast, nonmedical students perceived SNSs to be inappropriate for educational purposes. There was consensus by the entire cohort that guidance, privacy, and supervision are needed for effective and professional use of SNSs for education.
Kind et al aimed to determine the presence of US medical schools on SNSs and the existence of policies that could explicitly address the use of social media. ${ }^{16}$ They deduced that all 132 (100\%) medical schools had websites and 95.45\% (126 of 132) had a Facebook presence. Only $13(10.16 \%)$ medical schools had guidelines that explicitly addressed policies about social media, particularly about forbidden or inappropriate material. The authors cautioned against the absence of strict guidelines for social media in higher education. The literature has raised concerns about the identity presentation and privacy concerns with Facebook. ${ }^{17}$ The current study also cautions against liberal use of SNSs, particularly by university students, due to the 
600

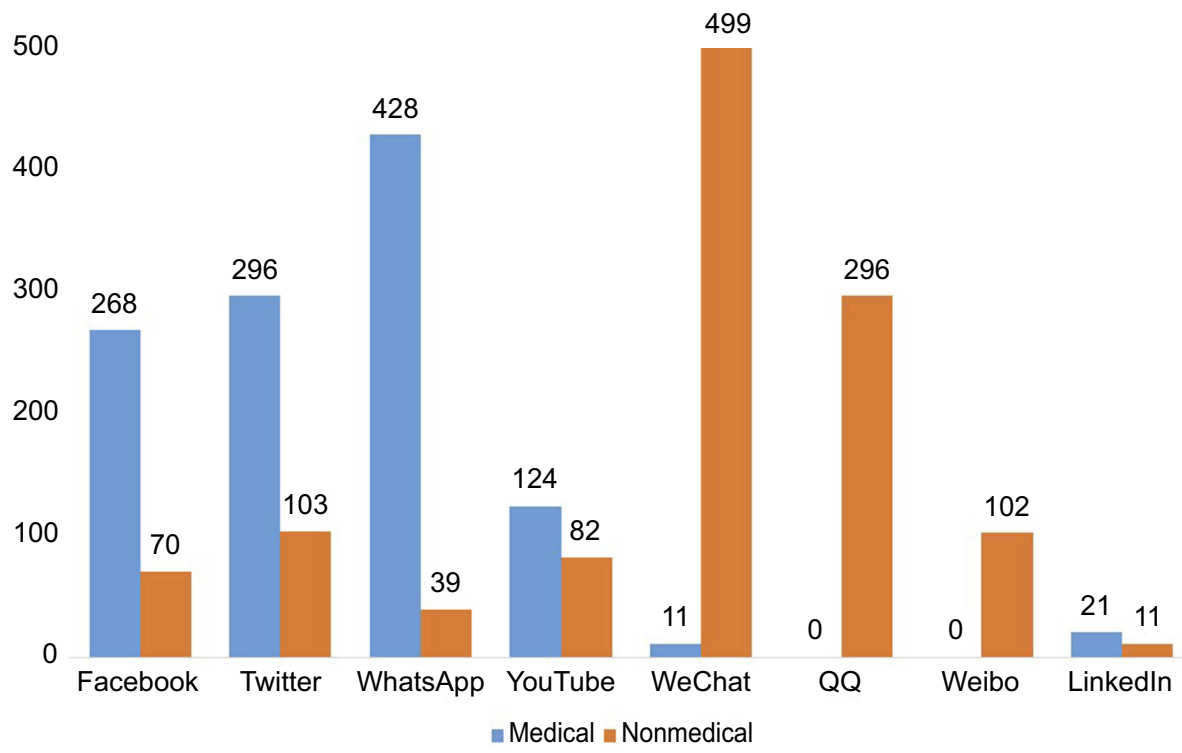

Figure 3 Most common social networking sites used by students for educational purposes $(n=2,350)$.

Table I Differences in perceptions about the usage of social networking sites from the study cohort measured by $\chi^{2}$ and normality tests $(n=2350)$

\begin{tabular}{|c|c|c|c|c|c|c|c|}
\hline \multirow[t]{2}{*}{ Statement } & \multicolumn{2}{|c|}{ Test of independence } & \multicolumn{5}{|c|}{ Kolmogorov-Smirnov normality test } \\
\hline & $\chi^{2}$ & $P$-value & Absolute & Positive & Negative & $\mathbf{Z}$ & $P$-value \\
\hline SI & $1,475^{\mathrm{a}}$ & $0 *$ & 0.24 & 0.18 & -0.24 & 11.69 & $0^{*}$ \\
\hline S2 & $471^{\mathrm{a}}$ & $0 *$ & 0.18 & 0.18 & -0.15 & 8.70 & $0 *$ \\
\hline S3 & $1,874^{\mathrm{b}}$ & $0 *$ & 0.31 & 0.23 & -0.31 & 15.20 & $0 *$ \\
\hline S4 & $296^{\mathrm{b}}$ & $0 *$ & 0.17 & 0.15 & -0.17 & 8.03 & $0 *$ \\
\hline S5 & $275^{c}$ & $0 *$ & 0.18 & 0.18 & -0.13 & 8.70 & $0 *$ \\
\hline S6 & $244^{c}$ & $0 *$ & 0.15 & 0.15 & -0.15 & 7.46 & $0^{*}$ \\
\hline S7 & $2,167^{d}$ & $0 *$ & 0.34 & 0.34 & -0.24 & 16.29 & $0 *$ \\
\hline S8 & $996^{\mathrm{e}}$ & $0 *$ & 0.29 & 0.29 & -0.15 & 13.84 & $0 *$ \\
\hline S9 & $963^{f}$ & $0 *$ & 0.27 & 0.27 & -0.14 & 13.27 & $0 *$ \\
\hline SIO & $550^{f}$ & $0 *$ & 0.22 & 0.22 & -0.11 & 10.85 & $0 *$ \\
\hline SII & $790^{g}$ & $0 *$ & 0.24 & 0.24 & -0.13 & 11.78 & $0^{*}$ \\
\hline $\mathrm{S} 12$ & $1,035^{\mathrm{h}}$ & $0 *$ & 0.29 & 0.29 & -0.16 & 13.97 & $0^{*}$ \\
\hline $\mathrm{SI} 3$ & $1,076^{i}$ & $0 *$ & 0.28 & 0.28 & -0.18 & 13.71 & $0 *$ \\
\hline SI 4 & $656^{j}$ & $0 *$ & 0.25 & 0.25 & -0.12 & 12.26 & $0 *$ \\
\hline SI5 & $902^{k}$ & $0^{*}$ & 0.27 & 0.27 & -0.15 & 13.27 & $0 *$ \\
\hline SI6 & $964^{j}$ & $0 *$ & 0.28 & 0.28 & -0.16 & 13.74 & $0 *$ \\
\hline SI7 & $208^{\prime}$ & $0 *$ & 0.20 & 0.20 & -0.14 & 9.45 & $0 *$ \\
\hline SI8 & $830^{\mathrm{m}}$ & $0 *$ & 0.28 & 0.28 & -0.14 & 13.29 & 0* \\
\hline S19 & $828^{n}$ & $0^{*}$ & 0.27 & 0.27 & -0.13 & 12.97 & $0^{*}$ \\
\hline S20 & $476^{\prime}$ & $0 *$ & 0.22 & 0.22 & -0.14 & 10.66 & $0 *$ \\
\hline S2I & $195^{\circ}$ & $0^{*}$ & 0.20 & 0.14 & -0.20 & 9.61 & $0^{*}$ \\
\hline
\end{tabular}

Notes: Degrees of freedom for all statements 4 . No cells had expected frequency <5. Minimum expected cell frequency: ${ }^{\mathrm{a}} 469.4 ;{ }^{\mathrm{b}} 469.6 ;{ }^{\mathrm{c}} 468.8 ;{ }^{\mathrm{d}} 468.0 ;{ }^{\mathrm{e}} 466.4 ;{ }^{\mathrm{f}} 468.2$; ${ }^{8} 463.8 ;{ }^{\mathrm{h}} 466.2 ;{ }^{i} 466.6 ;{ }^{i} 467.2 ;{ }^{\mathrm{k}} 466.8 ;{ }^{\mathrm{i}} 467.4 ;{ }^{\mathrm{m}} 464.8 ;{ }^{\mathrm{n}} 464.2 ;{ }^{\circ} 463.6$. ${ }^{*}$ Indicates the variable is significant at $5 \%$ level of significance. 
Table 2 Validity and reliability of statements

\begin{tabular}{|l|l|l|l|l|}
\hline Factor & Eigenvalues & \% of variance & Cronbach's $\boldsymbol{\alpha}$ & Number of items \\
\hline SNSs for education & 8.66 & 41.23 & 0.786 & 13 (S2-S9, SII-SI4, and SI6) \\
Professional development & 2.25 & 10.74 & 0.839 & 2 (SI0 and SI5) \\
Effectiveness of SNSs for education & 1.29 & 6.15 & 0.882 & $3(\mathrm{SI}-\mathrm{S} 19)$ \\
\hline Kaiser-Meyer-Olkin measure of sampling adequacy 0.94 \\
Bartlett's test of sphericity $\left(\chi^{2}\right) 29192^{*}$
\end{tabular}

Notes: The remaining 3 statements (SI, S20, and S2I) are stand alone and unable to apply this test on these statements. *Indicates the variable is significant at $5 \%$ level of significance.

Table 3 Results of Mann-Whitney $U$ tests showing comparison of students' perceptions about the usage of social networking sites (SNSs) among medical vs nonmedical students $(n=2,350)$

\begin{tabular}{|c|c|c|c|c|c|c|c|}
\hline \multirow[t]{2}{*}{ Factors } & \multicolumn{2}{|c|}{ Medical } & \multicolumn{2}{|c|}{ Nonmedical } & \multirow[t]{2}{*}{$U$} & \multirow[t]{2}{*}{$\mathbf{Z}$} & \multirow{2}{*}{$\begin{array}{l}P \text {-value } \\
\text { (two-tailed) }\end{array}$} \\
\hline & MR & $\mathbf{n}$ & MR & $\mathbf{n}$ & & & \\
\hline Friends and family & 1,134 & $\mathrm{I}, 148$ & 1218 & 1,202 & 640,564 & -3.18 & $0 *$ \\
\hline SNSs for education & 1,328 & $\mathrm{I}, 148$ & 978 & $\mathrm{I}, 202$ & 566,153 & -7.03 & $0^{*}$ \\
\hline Professional development & 1,298 & 1,142 & $\mathrm{I}, 055$ & $\mathrm{I}, 202$ & 516,148 & -10.60 & $0 *$ \\
\hline SNSs useful for education & 1,218 & 1,136 & 1,123 & 1,296 & 581,288 & -5.95 & $0 *$ \\
\hline Need supervision & 1,276 & 1,136 & $\mathrm{I}, 068$ & $\mathrm{I}, 20 \mathrm{I}$ & 560,722 & -7.70 & $0 *$ \\
\hline Inappropriate for education & 1,117 & $\mathrm{I}, 147$ & 1,229 & $\mathrm{I}, 20 \mathrm{I}$ & 623,308 & -4.16 & $0 *$ \\
\hline
\end{tabular}

Notes: Total number of medical and nonmedical students I, I48 and I,202 respectively. Sample size less fewer in number due to missing values. *Indicates the variable is significant at $5 \%$ level of significance.

availability of uncensored and indecent material on these platforms. The amount of information shared on Facebook by clients in an open and insecure manner in the absence of privacy codes certainly exposes users to risk. ${ }^{18}$ Despite the perceived risks, its interwoven relationship with students in higher education signals the importance of Facebook in facilitating learning and keeping in touch with alumni and offline communities. $^{19}$

In the present study, 1,271 of 2,350 (54.08\%) students used SNSs for keeping in touch with their colleagues and instructors three to five times a day. In addition, 647 of $2,350(27.53 \%)$ used SNSs for sharing study-related material once a week, 546 of 2,350 (23.23\%) three to five times a day, and 561 of 2,350 (23.87\%) once a day. Several reports have shown that $94 \%$ of college students using Facebook spent an average of 10-30 minutes per day on the site and had approximately $150-200$ friends. $^{20-22}$ However, the precise nature of SNS use for various purposes is hard to define. Course-management systems like Moodle and Blackboard, with SNSs as e-learning platforms, se have been found to be more focused and lack the customized features of individual touch and networking flexibility that SNSs offer. ${ }^{22}$ SNSs are user-centered, rather than class-centered, with great promise to enhance student engagement by encouraging rapid development of virtual communities and extending learning opportunities beyond physical classroom boundaries. ${ }^{10,23}$ Correia and Davis $^{24}$ pointed out the effectiveness of SNSs in developing sound instructional practice for distance-education courses that facilitate the key concept of creating learners' communities.

Our study showed that medical students use SNSs effectively during the pre-exam period for instant help, while nonmedical students use SNSs effectively for sharing lecture notes. Despite knowledge about the effectiveness of SNSs for learning, only 624 (26.6\%) students were making use of these platforms for their education, of which a majority were medical students: 362 of 624 (58\%). This signals poor understanding of the study cohort about the outright benefits of SNSs. The utility of SNSs in education can be enhanced by focused educational reforms that foster interprofessional education and practice pitched appropriately, with the desired characteristics of professionalism and medical ethics. ${ }^{25-28}$ SNSs carry more value in distance-learning courses where virtual e-learning platforms provide core curricula by telementoring and remote access. ${ }^{29}$ A fundamental intervention for embedding social media in instructional pedagogies would be to modify workplace-based teaching and learning that have 
been reported to be the most effective educational strategy in higher education. ${ }^{30}$

Our study found that WhatsApp was the most common SNS used for education by 428 of 1,148 (37.28\%) medical students and WeChat the most common social media preferred by 499 of 1,202 (41.51\%) nonmedical students for learning and sharing educational material. Although WeChat has emerged as a fascinating educational tool in medicine ${ }^{31}$ and other disciplines, ${ }^{32}$ surprisingly the cohort of Saudi medical students did not prefer this social media for their learning. This might be influenced by limited permission to use WeChat for the Saudi cohort and restrictions on WhatsApp by the Chinese government. These findings call for further research to determine a standard social media platform that can be tailored to meet the learning needs of university students across regions and disciplines.

Other key findings in our research signaled significantly greater use of social media by medical than nonmedical students. Interestingly, most of the nonmedical students perceived SNSs to be inappropriate for educational purposes. Such significant variations in perceptions and use of SNSs could be drived by regional and educational backgrounds of the respondents, as well as different disciplines and institutional policies. These findings underpin the value of further studies that can explore the educational needs of learners that can help in better understanding of the educational use of SNSs in education.

The use of SNSs is not without problems. Cartledge et al argued that although SNSs have been seamlessly incorporated in education and has received positive feedback the, literature has not shown concrete evidence that social media is more effective than conventional educational resources. ${ }^{33}$ Similarly, other studies have raised concerns about the demerits of social media in education, with particular reference to privacy and addiction. ${ }^{34,35}$ This signifies the need for more evidence-based interventional studies that can highlight the effectiveness of incorporating SNSs in education. From a different perspective, understanding learners' needs by capturing viewpoints about their learning preferences will certainly help educators in modifying curricula in the right direction. ${ }^{36}$

\section{Study limitations}

The significant variations in extent and pattern of use of SNSs by medical and nonmedical cohorts from two countries might have been influenced by cultural context. At the same time, the choice of platform and motivation for using a particular SNS application may be determined by the availability and flexibility of its usage. These shortcomings should be considered while conducting future research in this domain.

\section{Conclusion}

This research has convincingly evaluated the seemingly unexplored educational benefits of SNSs perceived by university students. Furthermore, the comparative data from medical and nonmedical students provide information about the popularity of various brands of SNSs in certain educational disciplines. Despite the high usage of SNSs for general purposes, educational use of these eplatforms was low. The findings of this study can be the first stepping stone toward initiating further interventional studies in determining the effectiveness of social media in education. At the same time, the diversity in using social media in our study cohort, even for learning conventions, indicates a lack of standard policy for incorporating a single digital platform into curricula across disciplines. Such findings can help educators to undertake necessary curricular reforms that can incorporate SNSs for educational purposes. However, supervised coaching and clear guidelines about the use of social media are warranted to maintain security, privacy, and professional usage.

\section{Author contributions}

All authors contributed to data analysis, drafting or revising the article, gave final approval of the version to be published, and agree to be accountable for all aspects of the work.

\section{Disclosure}

The authors report no conflicts of interest in this work.

\section{References}

1. Dong T, Liang C, He X. Social media and internet public events. Telematics Informatics. 2017;34(3):726-739. doi:10.1016/j.tele.2016. 05.024

2. Villacampa J, Ingram GP, Martí-Vilar M, Olivera-La Rosa A. An investigation of facebook users' implicit associations between Facebook, sexual and prosocial behavior. Heliyon. 2018;4(9):e00811. doi:10.1016/j.heliyon.2018.e00811

3. Escobar-Viera CG, Shensa A, Bowman ND, et al. Passive and active social media use and depressive symptoms among United States adults. Cyberpsychol Behav Soc Netw. 2018;21(7):437-443. doi:10.1089/cyber.2017.0668

4. Price AM, Devis K, LeMoine G, Crouch S, South N, Hossain R. First year nursing students use of social media within education: results of a survey. Nurse Educ Today. 2018;61:70-76. doi:10.1016/j.nedt.2017. 10.013 
5. Manca S, Ranieri M. Implications of social network sites for teaching and learning. Where we are and where we want to go. Edu Info Tech. 2017;22(2):605-622. doi:10.1007/s10639-015-9429-x

6. Hughes AL, Palen L. Twitter adoption and use in mass convergence and emergency events. Int J Emergency Manag. 2009;6(3-4):248260. doi:10.1504/IJEM.2009.031564

7. Huang C. Social network site use and academic achievement: A meta-analysis. Comput Educ. 2018;119:76-83. doi:10.1016/j. compedu.2017.12.010

8. Guraya SY. The usage of social networking sites by medical students for educational purposes: A meta-analysis and systematic review. $N$ Am J Med Sci. 2016;8(7):268. doi:10.4103/1947-2714.187131

9. Aydin S. Foreign language learners' interactions with their teachers on facebook. System. 2014;42:155-163. doi:10.1016/j.system. 2013.12.001

10. Liu -C-C, Chen Y-C, Tai S-JD. A social network analysis on elementary student engagement in the networked creation community. Comput Educ. 2017;115:114-125. doi:10.1016/j.compedu.2017.08.002

11. Mazer JP, Murphy RE, Simonds CJ. I'll see you on "Facebook": the effects of computer-mediated teacher self-disclosure on student motivation, affective learning, and classroom climate. Commun Educ. 2007;56(1):1-17. doi:10.1080/03634520601009710

12. Akçayır G, Akçayır M. Research trends in social network sites' educational use: a review of publications in all SSCI journals to 2015. Rev Edu. 2016;4(3):293-319. doi:10.1002/rev3.2016.4.issue-3

13. Koh C. Exploring the use of web 2.0 technology to promote moral and psychosocial development: can YouTube work? $\mathrm{Br} J \mathrm{Educ}$ Technol. 2014;45(4):619-635. doi:10.1111/bjet.2014.45.issue-4

14. Brady KP, Holcomb LB, Smith BV. The use of alternative social networking sites in higher educational settings: A case study of the elearning benefits of Ning in education. J Interact Online Learn. 2010;9(2):151-170.

15. Guraya SY, Almaramhy H, Al-Qahtani MF, Guraya SS, Bouhaimed M, Bilal B. Measuring the extent and nature of use of Social Networking Sites in Medical Education (SNSME) by university students: results of a multi-center study. Med Educ Online. 2018;23 (1):1505400. doi:10.1080/10872981.2018.1505400

16. Kind T, Genrich G, Sodhi A, Chretien KC. Social media policies at US medical schools. Med Educ Online. 2010;15(1):5324 doi:10.3402/meo.v15i0.5324

17. Gross R, Acquisti A, editors. Information revelation and privacy in online social networks. Proceedings of the 2005 ACM workshop on Privacy in the electronic society. Pittsburgh, PA, USA: ACM; 2005.

18. Hewitt A, Forte A Crossing boundaries: identity management and student/faculty relationships on the Facebook. Poster presented at CSCW, Banff, Alberta, Canda. 2006:1-2.

19. Crymble A. An analysis of Twitter and Facebook use by the archival community. Archivaria. 2010;70:125-151.

20. Tess PA. The role of social media in higher education classes (real and virtual) - A literature review. Comput Human Behav. 2013;29(5): A60-A8. doi:10.1016/j.chb.2012.12.032

21. Hargittai E. Whose space? Differences among users and non-users of social network sites. J Comput Mediat Commun. 2007;13(1):276297. doi:10.1111/j.1083-6101.2007.00396.x
22. Ellison NB, Steinfield C, Lampe C. The benefits of Facebook "friends:" Social capital and college students' use of online social network sites. J Comput Mediat Commun. 2007;12(4):1143-1168. doi:10.1111/jcmc.2007.12.issue-4

23. Smith MA, Shneiderman B, Milic-Frayling N, et al., editors. Analyzing (social media) networks with NodeXL. Proceedings of the fourth international conference on Communities and technologies. Pennsylvania, PA, USA: ACM; 2009.

24. Correia AP, Davis N. Intersecting communities of practice in distance education: the program team and the online course community. Dist Edu. 2008;29(3):289-306. doi:10.1080/01587910802395813

25. Al-Qahtani MF, Guraya SY. Measuring the attitudes of healthcare faculty members towards interprofessional education in KSA. $J$ Taibah Uni Med Sci. 2016;11(6):586-593. doi:10.1016/j.jtumed. 2016.10.001

26. Guraya SY, Norman RI, Roff S. Exploring the climates of undergraduate professionalism in a Saudi and a UK medical school. Med Teach. 2016;38(6):630-632. doi:10.3109/0142159X.2016.1150987

27. Guraya SY, London N, Guraya SS. Ethics in medical research. $J$ Microsc Ultrastruct. 2014;2(3):121-126. doi:10.1016/j.jmau.2014. 03.003

28. Guraya SY, Norman RI, Khoshhal KI, Guraya SS, Forgione A. Publish or Perish mantra in the medical field: A systematic review of the reasons, consequences and remedies. Pakistan J Med Sci. 2016;32(6):1562. doi:10.12669/pjms.326.10490

29. Forgione A, Kislov V, Guraya SY, Kasakevich E, Pugliese R. Safe introduction of laparoscopic colorectal surgery even in remote areas of the world: the value of a comprehensive telementoring training program. J Laparoendosc Adv Surg Tech. 2015;25(1):37-42. doi:10.1089/lap.2014.0191

30. Guraya SY. Workplace-based assessment; applications and educational impact. Malays J Med Sci. 2015;22(6):5.

31. Zeng F, Deng G, Wang Z, Liu L. WeChat: a new clinical teaching tool for problem-based learning. Int $J$ Med Edu. 2016;7:119. doi:10.5116/ijme.5708.e5c4

32. Liu Z. A Study on the Application of WeChat in ESP Training. Theory Practice Lang Stud. 2014;4(12):2549. doi:10.4304/ tpls.4.12.2549-2554

33. Cartledge P, Miller M, Phillips B. The use of social-networking sites in medical education. Med Teach. 2013;35(10):847-857. doi:10. 3109/0142159X.2013.804909

34. Schroeder A, Minocha S, Schneider C. The strengths, weaknesses, opportunities and threats of using social software in higher and further education teaching and learning. J Comput Assist Learn. 2010;26(3):159-174. doi:10.1111/j.1365-2729.2010.00347.x

35. Song I, Larose R, Eastin MS, Lin CA. Internet gratifications and Internet addiction: on the uses and abuses of new media. Cyberpsychol Behav. 2004;7(4):384-394. doi:10.1089/cpb.2004.7. 384

36. Guraya SY, Forgione A, Sampogna G, Pugliese R. The mapping of preferred resources for surgical education: perceptions of surgical trainees at the Advanced International Minimally Invasive Surgery Academy (AIMS), Milan, Italy. J Taibah Uni Med Sci. 2015;10 (4):396-404. doi:10.1016/j.jtumed.2015.10.003 


\section{Publish your work in this journal}

Psychology Research and Behavior Management is an international, peer-reviewed, open access journal focusing on the science of psychology and its application in behavior management to develop improved outcomes in the clinical, educational, sports and business arenas. Specific topics covered in the journal include: Neuroscience, memory and decision making; Behavior modification and management; Clinical applications; Business and sports performance management; Social and developmental studies; Animal studies. The manuscript management system is completely online and includes a very quick and fair peer-review system, which is all easy to use. Visit http://www. dovepress.com/testimonials.php to read real quotes from published authors. 